\title{
New technologies for indeterminate biliary strictures
}

\author{
Roberto Oleas, Juan Alcívar-Vasquez, Carlos Robles-Medranda
}

Gastroenterology and Endoscopy Division, Instituto Ecuatoriano de Enfermedades Digestivas (IECED), Guayaquil, Ecuador

Contributions: (I) Conception and design: All authors; (II) Administrative support: None; (III) Provision of study materials or patients: None; (IV) Collection and assembly of data: None; (V) Data analysis and interpretation: None; (VI) Manuscript writing: All authors; (VII) Final approval of manuscript: All authors.

Correspondence to: Carlos Robles-Medranda, MD. Head of the Endoscopy Division, Instituto Ecuatoriano de Enfermedades Digestivas, Av. Abel Romeo Castillo S/N y Av. Juan Tanca Marengo, Torre Medica II, Office 405-406, Guayaquil 090505, Ecuador. Email: carlosoakm@yahoo.es.

\begin{abstract}
An early and accurate diagnosis of biliary strictures yields optimal patient outcomes; however, endoscopic retrograde cholangiopancreatography (ERCP) with cytobrush/biopsy forceps has low sensitivity with a high number of false negatives. Various attempts to improve the accuracy of diagnosing indeterminate biliary strictures though ERCP-guided specimen acquisition have been proposed, such as with the use of fluorescence in situ hybridization, an endoscopic scraper, and the wire-grasping method, with modest to large improvements in sensitivity. Direct visualization of the biliary tree during peroral cholangioscopy has shown high sensitivity and specificity for the differentiation of neoplastic and non-neoplastic biliary lesions; however, there is no consensus on the visual characteristics of neoplastic lesions and moderate agreement between observers. Peroral cholangioscopy system (POCS)-guided specimen acquisition using forceps has shown inferior sensitivity compared to the visual characteristics; however, the specificity remains high. Optimal specimen processing with onsite evaluations and touch imprint cytology have been shown to improve the sensitivity and accurately diagnose nearly $90 \%$ of patients. In vivo evaluations of biliary strictures with probe-based confocal laser endomicroscopy have demonstrated high sensitivity with modest specificity for malignant biliary strictures. Optical computed tomography described reproductible criteria for malignancy detection in biliary strictures, increasing the sensitivity during ERCP evaluations. Differentiating benign causes from malignant causes of biliary strictures is a challenging task in clinical practice, with various concerns that still need to be addressed. Efforts should be made to define each diagnostic method's role in the evaluation of indeterminate biliary strictures.
\end{abstract}

Keywords: Common bile duct neoplasms; common bile duct diseases; cholangiocarcinoma

Received: 12 November 2019; Accepted: 12 March 2020; Published: 25 April 2022.

doi: $10.21037 / \operatorname{tgh} .2020 .03 .05$

View this article at: http://dx.doi.org/10.21037/tgh.2020.03.05

\section{Introduction}

Indeterminate biliary strictures are a diagnostic challenge for endoscopists. Endoscopic retrograde cholangiopancreatography (ERCP) with brush cytology and biopsy has been the standard of care for the evaluation of biliary strictures; however, this approach has a low sensitivity for defining malignancies in these strictures and fails to accurately diagnose $55 \%$ of patients (1). Additionally, low-sensitivity tests prevent early diagnosis and the provision of treatment for malignant strictures, thus delaying surgical interventions or leading to repeated interventions and increasing the healthcare-related cost.

Both malignant and benign conditions should be considered in the differential diagnosis of indeterminate biliary strictures, considering that their management approaches differ significantly, and up to $30 \%$ of patients with cholangiocarcinoma have a negative initial sample $(1,2)$. We aimed to review the available data on new technologies for the management of indeterminate biliary strictures and the impact of these technologies on the clinical management of these patients. 


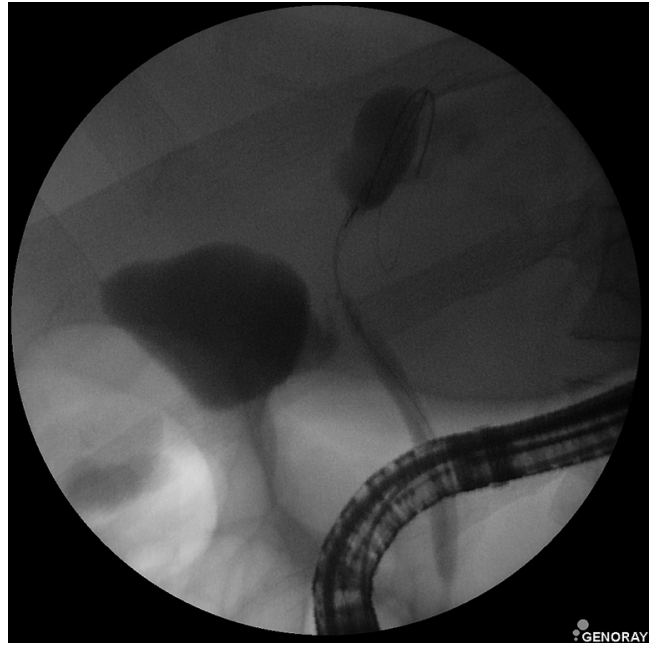

Figure 1 Fluoroscopic evaluation of an indeterminate biliary stricture in the proximal common bile duct (original source from the authors).

\section{Indeterminate biliary strictures}

Biliary strictures are defined as indeterminate when the biliary strictures have no overt mass on noninvasive imaging [computed tomography or magnetic resonance cholangiopancreatography (MRCP)] and cannot be distinguished as malignant or benign after ERCP fluoroscopic evaluations (Figure 1) with standard brush cytology and/or forceps biopsy (3). The differential diagnoses of indeterminate biliary strictures are extensive, ranging from neoplastic to non-neoplastic conditions. Additionally, biliary strictures can originate as external compression from the extrahepatic biliary tree, pancreas, liver, gallbladder, ampulla, regional lymph nodes, or metastasis.

\section{Biliary brush cytology and intraductal biopsy}

ERCP with brush cytology and intraductal biopsies are routinely performed for the evaluation of malignantappearing biliary strictures; however, a recent meta-analysis showed that both procedures had limited sensitivity for the diagnosis of biliary strictures (45\% for brush cytology and $48 \%$ for intraductal biopsies) and the combination of both techniques modestly increased the sensitivity to $59.4 \%$. However, these modalities had a $100 \%$ specificity for confirming malignancies (1). Currently, there are wire-guided assisted endobiliary forceps (US Endoscopy, Steris company, Ohio, USA) that enable the placement of the forceps into the biliary system along a guidewire, with the aim to improve tissue acquisition (4); however, prospective studies that evaluate this promising tool for tissue acquisition and compare the tool with peroral cholangioscopy system (POCS)-guided biopsy are needed before clinical guidelines can be established.

\section{Fluorescence in situ hybridization (FISH)}

FISH evaluates the presence of chromosomal abnormalities in cells obtained during biliary brushing. Various chromosomal abnormalities have been described, including aneuploid chromosomal regions on chromosomes 3, 7, and 17 (CEP 3,7,17) and deletion of the 9p21 locus (p16). In a recent 10 -year retrospective study of 281 patients, combined cytology and FISH reached a $63 \%$ sensitivity and $98 \%$ specificity. The authors suggest the sequential FISH analysis for patients with distal biliary strictures and negative cytology results, whereas they recommend that cytology and FISH analyses should be performed directly in patients with proximal biliary strictures $(5,6)$.

\section{Endoscopic scraper}

Endoscopic devices with scraping loops have been proposed for the sampling of biliary strictures (Figure 2) and have obtained adequate samples in $93 \%$ of patients; however, it only detects $65 \%$ of biliary neoplasia. Interestingly, this endoscopic device with scrapping loops had significantly higher rates of sample acquisition and cancer detection than biopsy forceps, identifying $48 \%$ of malignant strictures that were false-negatives when biopsy forceps were used alone (7). This type of endoscopic device could be considered a first-line tissue-sampling tool for biliary strictures in centers where other diagnostic methods are not available. In a recent study, one endoscopic scraper device (Trefle ${ }^{\circledR}$, Piolax Medical Devices Inc., Yokohama, Japan) was compared to a POCS-guided tissue acquisition forceps; the paper described an $87.5 \%$ adequate tissue acquisition rate for the endoscopic scraper, with an $83 \%$ sensitivity and $86 \%$ specificity, whereas the POCSguided forceps biopsy reached a $90 \%$ sufficient sample rate, sensitivity, and specificity. The authors noted that endoscopic sphincterotomy was performed in fewer patients who underwent sampling using the endoscopic scraper than in those who underwent sampling with the POCS-guided forceps, and the endoscopic scraper might help to preserve the sphincter of Oddi (8). 

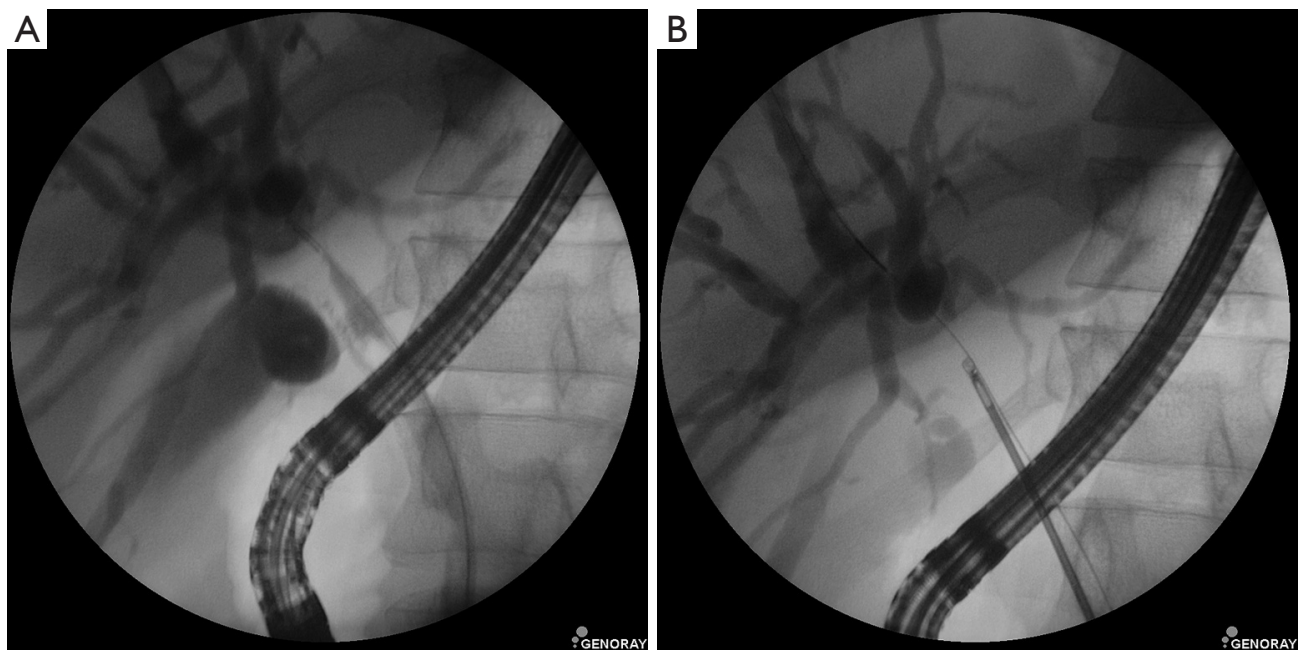

Figure 2 Fluoroscopic evaluation with a biliary stricture in the hilum (A) and guide-wire biliary forceps specimen acquisition (B) (original source from the authors).

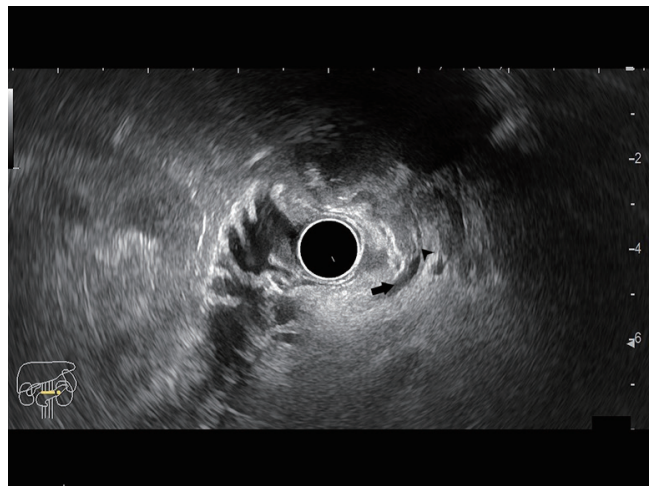

Figure 3 Endoscopic ultrasound evaluation of a biliary stricture (arrowhead) in the proximal common bile duct (arrow) (original source from the authors).

In a randomized trial, the wire-grasping method for obtaining an adequate specimen for histology evaluations was significantly superior to the direct ERCP forceps biopsy method, with a $91 \%$ sensitivity and $100 \%$ specificity and a $93 \%$ detection rate for neoplasia (9).

\section{Endoscopic ultrasound fine-needle aspiration (EUS-FNA)}

EUS-FNA has been indicated to be a safe procedure as a first-line modality for obtaining histological samples from biliary lesions (Figure 3) and had an $87 \%$ sensitivity and $87 \%$ accuracy in a prospective, single-center trial (10). In another single-center study, EUS-FNA was proven to be significantly superior to ERCP with brush cytology and forceps biopsy $(93.8 \%$ sensitivity and $94 \%$ accuracy versus $60 \%$ sensitivity and $62 \%$ accuracy, $\mathrm{P}=0.034$ ). However, when these two procedures were combined in a single session, they reached a $97.9 \%$ sensitivity and $98 \%$ accuracy (11). However, this approach is limited for intrahepatic strictures or proximally located strictures and has better outcomes for distal and extraductal lesions and those larger than $15 \mathrm{~mm}(11)$.

\section{POCS}

A single-operator POCS can be inserted into the common bile duct to allow for direct visualization and to obtain targeted biopsies. In a recent meta-analysis, a firstgeneration single-operator POCS that was based on a fiberoptic device reached an $84 \%$ pooled sensitivity and $83 \%$ pooled specificity for the diagnosis of malignant biliary strictures, whereas cholangioscopy-guided biopsies achieved a $60 \%$ sensitivity and $98 \%$ specificity (12).

Then, a digital version of the single-operator cholangioscope (Spyglass DS, Boston Scientific, Malborough, MA, USA) improved the image quality and provided a wider endoscopic field of view than the first generation POCS. This system includes an aspiration and irrigation channel, which enables less traumatic advancement across the papilla and strictures. In a retrospective analysis comparing fiberoptic cholangioscopy and digital cholangioscopy, the latter exhibited a 


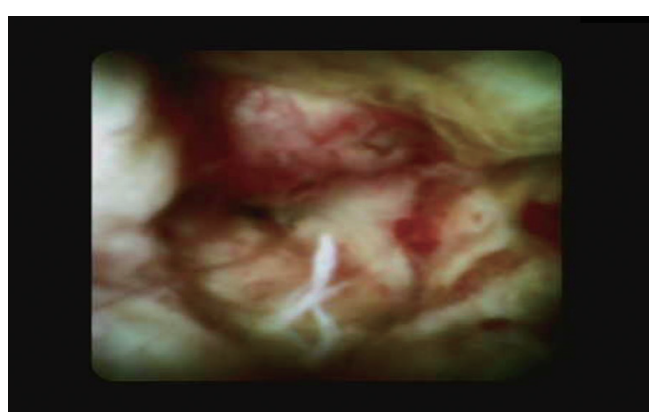

Figure 4 A biliary lesion evaluated under direct visualization via peroral cholangioscopy: a mass lesion with the presence of irregular and tortuous vessels (suggestive of a malignancy) (original source from the authors).

significantly superior diagnostic yield (13). In a recent metaanalysis of a digital single-operator cholangioscope that involved 335 patients, the visual characterization reached a $90 \%$ sensitivity and $87 \%$ specificity for the diagnosis of indeterminate biliary lesions, whereas POCS-guided biopsy reached a $69 \%$ sensitivity and $98 \%$ specificity (14). In another meta-analysis, the accuracy of the POCS was $89 \%$ for making a visual diagnosis and $79 \%$ for making a histological diagnosis (15).

Regarding safety, POCS is a safe procedure with an adverse event rate of $7 \%$; however, it leads to a higher incidence of cholangitis than ERCP; thus, the routine use of antibiotics is indicated for POCS (16).

\section{POCS-guided biopsy forceps}

Intraductal forceps biopsy sampling during POCS can be performed using the SpyBite ${ }^{\circledR}$ forceps (Boston Scientific, Malborough, USA); however, the diagnostic outcomes differ among various studies with sensitivities ranging from $58 \%$ to $86 \%$ and specificities from $90 \%$ to $100 \%$ for digital cholangioscope-guided biopsy $(17,18)$. One factor that influences this may be the number of biopsy passes performed during POCS and the cholangioscope device used. Interestingly, POCS-guided biopsy has shown inferior sensitivity values compared to the visual characterization with POCS, which is probably related to the lack of an optimal technique for specimen processing and an unknown number of biopsies required to establish an accurate diagnosis. In a recent meta-analysis of POCSguided biopsies for the diagnosis of biliary malignancies in 539 patients, the pooled sensitivity was $71.9 \%$, and the pooled specificity was $99.1 \%$ (19).

The rapid onsite evaluation of touch imprint cytology
(ROSE-TIC) for POCS-guided biopsies of indeterminate biliary strictures showed a $93.5 \%$ diagnostic accuracy $[100 \%$ sensitivity, $88.9 \%$ specificity, $86.7 \%$ positive predictive value (PPV) and $100 \%$ negative predictive value (NPV)]. This technology is limited by the availability of an on-site cytopathologist and the associated costs; however, ROSETIC may benefit centers that rely mainly on ERCP-guided biopsies and lack other techniques (20).

Recently, in a randomized control trial evaluating the optimal specimen processing method (onsite or offsite) and the number of biopsies needed to establish a definite diagnosis, researchers found no significant difference between offsite and onsite processing in terms of diagnostic accuracy; however, onsite evaluations required one biopsy to provide a diagnosis, compared to the 3 or 4 biopsies needed for offsite specimen evaluations. Based on these findings, the authors suggest that for centers without onsite cytopathology support, 3 POCS-guided biopsies of biliary strictures should be obtained for offsite evaluations to accurately diagnose $90 \%$ of the cases (21).

\section{Cholangioscopic features of neoplasia}

Since the development of POCS, various morphological elements of the strictures during POCS visualization have been proposed to predict malignancy, such as the presence of papillary projections, intraductal nodules or mases (Figure 4), infiltrative or ulcerated strictures, irregular surface or irregular, dilated, and tortuous vasculature (tumor vessels). However, the agreement between expert endoscopists has been shown to be slight when criteria such as the surface structure, vessels, lesions, and visual findings were applied, demonstrating the necessity for formally established and validated visual criteria for benign and malignant biliary disorders (22).

Sethi et al. in a two-phase study, defined the terminology for visual criteria during cholangioscopy by consensus of 12 expert biliary endoscopists into eight categories: the presence of stricture, presence of a lesion, mucosa features, papillary projections, ulceration, abnormal vessels, scarring and pronounced pit. During the validation process, in multivariable analysis ulceration and papillary projections criteria were the only features found to be significantly associated with the diagnosis of malignancy (23).

\section{Cholangioscopy classification system}

Recently, a novel classification system using POCS for 


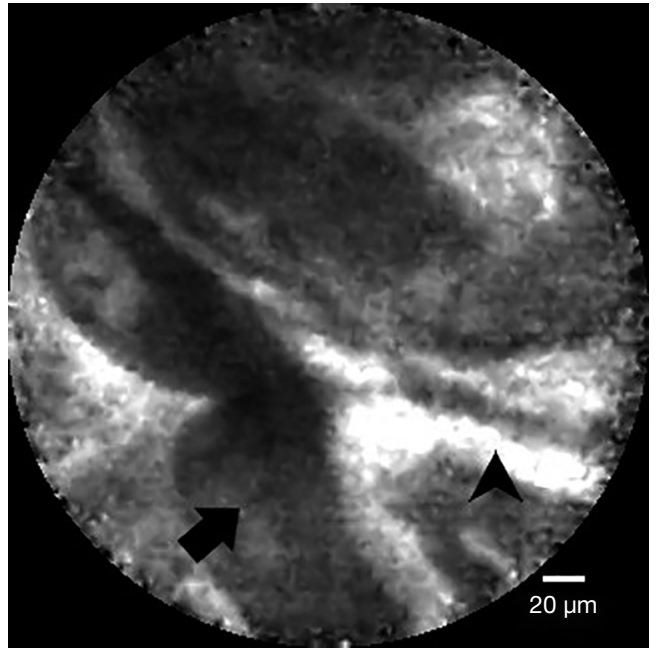

Figure 5 Probe-based confocal laser endomicroscopy evaluation of a biliary lesion: the presence of thick dark bands $>40 \mu \mathrm{m}$ (arrow) and thick white band $>40 \mu \mathrm{m}$ (arrowhead) suggestive of malignancy (original source from the authors).

the diagnosis of bile duct lesions was proposed, including seven types of lesions divided into two main categories (neoplastic and non-neoplastic) based on the morphological and vascular patterns (24). This classification system reached a $96.3 \%$ sensitivity and $92.3 \%$ specificity, with high reproducibility among observers. For non-neoplastic lesions, the authors proposed three types of lesion patterns: a villous, a polypoid, and an inflammatory pattern without the presence of irregular vascularity. However, for neoplastic lesions, they proposed a flat pattern, a polypoid pattern, and a honeycomb pattern, and all patterns had irregular or spider neovascularity.

\section{Vascularity as a single predictor of neoplasia}

The presence of bleeding, oozing, or tortuous vessels as indicators of "tumoral vessels" has been considered one of the most reliable cholangioscopic findings of malignancy. The term "tumor vessel" was first described by Yamase et al., who defined these vessels as abnormal, irregular, and serpentine vascular structures adjacent to the mucosa of malignant lesions that are synthetized de novo for nutritional purposes (25).

In various recent prospective trials, the presence of irregular vessels has been identified as one of the most common features of malignancy (26). Interestingly, in the current POCS classification system, this feature was shared among the four proposed types for neoplastic biliary strictures. Prat et al. suggested that the presence of irregular or spider vascularity should be enough to predict the occurrence of neoplasia (27).

In a recent study from our research group, we evaluated neovascularity as a single cholangioscopic feature of neoplasia and found a high sensitivity and NPV (94\% and $90 \%$, respectively). However, an inferior specificity (63\%) and PPV (75\%) were encountered in comparison to those of the POCS classification system; we believe this might be influenced by the exclusion of other POCS visual features (28). Additionally, a benign condition such as Ig-G4-related sclerosing cholangitis and severe mucosa inflammation might show tortuous vessels; however, the morphology of the vessels rather than its presence should be considered when predicting malignancies in biliary strictures (29).

Establishing a single feature for malignant biliary strictures may facilitate an adequate diagnosis, guide biopsy specimen acquisition, and improve interobserver agreement, considering that modern digital POCS offer an accurate visualization of the intraductal vessels.

\section{Economic impact of peroral cholangioscopy}

Recently, an economic analysis from Belgium compared the ERCP+ brushing diagnostic method and POCS methods. Considering a $45 \%$ sensitivity for ERCP+ brushing and an $86 \%$ sensitivity for POCS, they found a lower number of procedures (-31\%) and costs (€265 per patient) in a decision tree for the stricture diagnosis model when POCS was used as the diagnosis method. Interestingly, in a simulation conducted with this model, an increase in the use of POCS may potentially save up to one patient in a cohort of 36 patients with malignancies, thereby increasing the overall survival to $17 \%(30)$.

\section{Probe-based confocal laser endomicroscopy (p-CLE)}

p-CLE provides an in vivo histological evaluation of the biliary mucosa (Figure 5) via a probe advanced through the cholangioscope working channel and a real-time endoscopic visualization of the histology of the biliary tree without the need for biopsy. This technique requires an intravenous contrast injection (fluorescein) to enhance the vascularsupplied mucosal structures.

Recently, in a meta-analysis of eight studies evaluating 
p-CLE for the diagnosis of indeterminate biliary strictures, $90 \%$ and $75 \%$ pooled sensitivity and specificity values were described, respectively (31). Interestingly, three studies used the Miami classification as the diagnostic criteria for the malignant biliary strictures, which was shown to have a $83 \%$ sensitivity and $77 \%$ specificity for the diagnosis of malignant biliary strictures (32). However, the Miami classification has a limited ability to differentiate between malignant and inflammatory strictures (33).

Therefore, Caillol et al. proposed the Paris classification, which aimed to provide a specific set of criteria to differentiate inflammatory strictures and malignancies and to reduce the number of false-positive strictures. They proposed four criteria to improve the accuracy of p-CLE for diagnosing benign inflammatory strictures: multiple thin white bands, dark granular pattern with scales, enlarged space between scales, and thickened reticular structures (34). Kahaleh et al. demonstrated that the specificity of p-CLE using the Paris classification in the diagnosis of indeterminate biliary strictures increased from $67 \%$ to $83.3 \%$ without impacting the overall accuracy of $83 \%$ (35).

However, one limitation is that this equipment is currently available in a limited number of tertiary centers, and no studies determining the role of p-CLE in combination with other methods, such as cholangioscopy, to improve the diagnostic accuracy of biliary neoplasia exist; however, an area of great interest is the economic impact of this technology in the management of biliary strictures.

\section{Optical coherence tomography (OCT)}

OCT consists of a probe that is advanced into the bile duct through a biliary catheter and using low-intensity infrared light produces a high-resolution in-vivo crosssectional image of the bile duct during ERCP evaluations. In malignant strictures, OCT depicted disorganized bile duct wall layers (unrecognizable layer architecture) and large nonreflective areas, suggesting the presence of tumor vessels. In a pilot study of patients with biliary strictures, the two OCT criteria for malignancy were encountered in $53 \%$ of patients, whereas at least one criterion could be found in $79 \%$ of patients. In this study, a $79 \%$ sensitivity and $69 \%$ specificity for defining malignancy was described for using both criteria (36). Recently, a second-generation OCT system using volumetric laser endomicroscopy (VLE) was introduced for the evaluation of biliary strictures during ERCP, in which epithelial thickening with projection and a hyper-reflective surface with shadowing, and layering effacement (loos of visualization and haziness of inner mucosal layers) were described in patients with confirmed cholangiocarcinoma (37). These preliminary observations demonstrate the feasibility and safety of additional OCT evaluation of biliary strictures; however, larger randomized trials are necessary to confirm the clinical impact of adding this technique to conventional ERCP with forceps biopsy/ cytobrush evaluation.

\section{Conclusions}

Accurately diagnosing biliary strictures is a challenging task during clinical practice. Patients may benefit from highsensitivity diagnostic methods to receive early curative therapy, which therefore improves mortality. Technology has advanced from low-sensitivity diagnostic techniques such as ERCP with conventional cytobrushing and biopsy sampling to more modern technologies that allow for the intraductal evaluation of strictures. However, the variability of the sensitivity of POCS and the agreement between observers has been found in various studies, probably because of the lack of a diagnostic criteria consensus for malignant biliary strictures for POCS. Specimen acquisition of distal biliary strictures can be performed via EUS with FNA, which is highly sensitive for distal biliary strictures when combined with ERCP.

Various attempts have been made to improve the sensitivity of the histological evaluations of the obtained specimens, such as the use of FISH, onsite specimen evaluations and ROSE-TIC, and have resulted in a modest improvement in sensitivity for FISH and a large improvement for ROSE-TIC. New technologies that aimed to offer the in vivo cellular evaluation of biliary strictures have been presented with high accuracy and specificity; however, these values are inferior compared to those of cholangioscopy. False-negatives during the histological assessment, cholangioscopy, and p-CLE significantly impacted the management of patients. First, it delayed early curative interventions, increasing the need for additional diagnostic methods and increased the morbidity and healthcare-related costs. There is no doubt that appropriate diagnostic and sampling methods lead to optimal management and reduce both overtreatment and undertreatment. The evaluation of indeterminate biliary strictures is a developing field of research with several concerns that still need be addressed. 


\section{Acknowledgments}

Funding: None.

\section{Footnote}

Provenance and Peer Review: This article was commissioned by the Guest Editor (Amy Tyberg) for the series "Innovation in Endoscopy" published in Translational Gastroenterology and Hepatology. The article has undergone external peer review.

Conflicts of Interest: All authors have completed the ICMJE uniform disclosure form (available at https://tgh.amegroups. com/article/view/10.21037/tgh.2020.03.05/coif). The series "Innovation in Endoscopy" was commissioned by the editorial office without any funding or sponsorship. CRM is a key opinion leader for Boston Scientific, and consultant for US Endoscopy. The authors have no other conflicts of interest to declare.

Ethical Statement: The authors are accountable for all aspects of the work in ensuring that questions related to the accuracy or integrity of any part of the work are appropriately investigated and resolved.

Open Access Statement: This is an Open Access article distributed in accordance with the Creative Commons Attribution-NonCommercial-NoDerivs 4.0 International License (CC BY-NC-ND 4.0), which permits the noncommercial replication and distribution of the article with the strict proviso that no changes or edits are made and the original work is properly cited (including links to both the formal publication through the relevant DOI and the license). See: https://creativecommons.org/ licenses/by-nc-nd/4.0/.

\section{References}

1. Navaneethan U, Njei B, Lourdusamy V, et al. Comparative effectiveness of biliary brush cytology and intraductal biopsy for detection of malignant biliary strictures: a systematic review and meta-analysis. Gastrointest Endosc 2015;81:168-76.

2. Rösch T, Hofrichter K, Frimberger E, et al. ERCP or EUS for tissue diagnosis of biliary strictures? A prospective comparative study. Gastrointest Endosc 2004;60:390-6.

3. Sethi A, Howell DA. The Indeterminate Biliary Stricture.
In: Chandrasekhara V, Khashab M, Elmunzer BJ, et al. editors. 3rd edition. Clinical Gastrointestinal Endoscopy. Elsevier, 2019 ;699-712.e4.

4. Kwon CI, Kim TH, Kim KA. Guide-wire assisted endobiliary forceps biopsy sampling. Clin Endosc 2017;50:404-5.

5. Brooks C, Gausman V, Kokoy-Mondragon C, et al. Role of Fluorescent In Situ Hybridization, Cholangioscopic Biopsies, and EUS-FNA in the Evaluation of Biliary Strictures. Dig Dis Sci 2018;63:636-44.

6. Gonda TA, Viterbo D, Gausman V, et al. Mutation Profile and Fluorescence in Situ Hybridization Analyses Increase Detection of Malignancies in Biliary Strictures. Clin Gastroenterol Hepatol 2017;15:913-919.e1.

7. Sakuma Y, Kodama Y, Sogabe Y, et al. Diagnostic performance of a new endoscopic scraper for malignant biliary strictures: a multicenter prospective study. Gastrointest Endosc 2017;85:371-9.

8. Kato M, Onoyama T, Takeda Y, et al. Peroral Cholangioscopy-Guided Forceps Biopsy and Endoscopic Scraper for the Diagnosis of Indeterminate Extrahepatic Biliary Stricture. J Clin Med 2019;8:873.

9. Yamashita Y, Ueda K, Kawaji Y, et al. The Wire-Grasping Method as a New Technique for Forceps Biopsy of Biliary Strictures: A Prospective Randomized Controlled Study of Effectiveness. Gut Liver 2016;10:642-8.

10. Onda S, Ogura T, Kurisu Y, et al. EUS-guided FNA for biliary disease as first-line modality to obtain histological evidence. Therap Adv Gastroenterol 2016;9:302-12.

11. Moura DTH, de Moura EGH, Matuguma SE, et al. EUS-FNA versus ERCP for tissue diagnosis of suspect malignant biliary strictures: a prospective comparative study. Endosc Int Open 2018;6:E769-77.

12. Navaneethan U, Hasan MK, Lourdusamy V, et al. Singleoperator cholangioscopy and targeted biopsies in the diagnosis of indeterminate biliary strictures: a systematic review. Gastrointest Endosc 2015;82:608-614.e2.

13. Mizrahi M, Khoury T, Wang Y, et al. "Apple Far from the Tree": comparative effectiveness of fiberoptic singleoperator cholangiopancreatoscopy (FSOCP) and digital SOCP (DSOCP). HPB 2018;20:285-8.

14. Sun $X$, Zhou Z, Tian J, et al. Is single-operator peroral cholangioscopy a useful tool for the diagnosis of indeterminate biliary lesion? A systematic review and meta-analysis. Gastrointest Endosc 2015;82:79-87.

15. Korrapati P, Ciolino J, Wani S, Shah J, et al. The efficacy of peroral cholangioscopy for difficult bile duct stones and indeterminate strictures: a systematic review and meta- 
analysis. Endosc Int Open 2016;4:E263-75.

16. Sethi A, Chen YK, Austin GL, et al. ERCP with cholangiopancreatoscopy may be associated with higher rates of complications than ERCP alone: a single-center experience. Gastrointest Endosc 2011;73:251-6.

17. Navaneethan U, Hasan MK, Kommaraju K, et al. Digital, single-operator cholangiopancreatoscopy in the diagnosis and management of pancreatobiliary disorders: a multicenter clinical experience (with video). Gastrointest Endosc 2016;84:649-55.

18. Turowski F, Hügle U, Dormann A, et al. Diagnostic and therapeutic single-operator cholangiopancreatoscopy with SpyGlassDSTM: results of a multicenter retrospective cohort study. Surg Endosc 2018;32:3981-8.

19. Badshah MB, Vanar V, Kandula M, et al. Peroral cholangioscopy with cholangioscopy-directed biopsies in the diagnosis of biliary malignancies. Eur J Gastroenterol Hepatol 2019;31:935-40.

20. Varadarajulu S, Bang JY, Hasan MK, et al. Improving the diagnostic yield of single-operator cholangioscopyguided biopsy of indeterminate biliary strictures: ROSE to the rescue? (with video). Gastrointest Endosc 2016;84:681-7.

21. Bang JY, Navaneethan U, Hasan M, et al. Optimizing Outcomes of Single-Operator Cholangioscopy-Guided Biopsies Based on a Randomized Trial. Clin Gastroenterol Hepatol 2020;18:441-448.e1.

22. Sethi A, Doukides T, Sejpal DV, et al. Interobserver agreement for single operator choledochoscopy imaging: can we do better? Diagn Ther Endosc 2014;2014:730731.

23. Sethi A, Tyberg A, Slivka A, et al. Digital Single-operator Cholangioscopy (DSOC) Improves Interobserver Agreement (IOA) and Accuracy for Evaluation of Indeterminate Biliary Strictures: The Monaco Classification. J Clin Gastroenterol 2022;56:e94-7.

24. Robles-Medranda C, Valero M, Soria-Alcivar M, et al. Reliability and accuracy of a novel classification system using peroral cholangioscopy for the diagnosis of bile duct lesions. Endoscopy 2018;50:1059-70.

25. Kim HJ, Kim MH, Lee SK, et al. Tumor vessel: A valuable cholangioscopic clue of malignant biliary stricture. Gastrointest Endosc 2000;52:635-8.

26. Shah RJ, Raijman I, Brauer B, et al. Performance of a fully disposable, digital, single-operator cholangiopancreatoscope. Endoscopy 2017;49:651-8.

27. Prat F, Napoleon B. Cholangioscopic diagnostic classification of bile duct lesions: a worthwhile task, not an easy one. Endoscopy 2018;50:1049-50.

28. Robles-Medranda C, Oleas R, Olmos JI, et al. 543 Is vascularity enough to predict neoplasia in bile duct lesions during peroral cholangioscopy? Gastrointest Endosc 2019;89:AB91.

29. Ishida Y, Itoi T, Okabe Y. Can image-enhanced cholangioscopy distinguish benign from malignant lesions in the biliary duct? Best Pract Res Clin Gastroenterol 2015;29:611-25.

30. Deprez PH, Garces Duran R, Moreels T, et al. The economic impact of using single-operator cholangioscopy for the treatment of difficult bile duct stones and diagnosis of indeterminate bile duct strictures. Endoscopy 2018;50:109-18.

31. Liu Y, Lu Y, Sun B, et al. Probe-based confocal laser endomicroscopy for the diagnosis of undetermined biliary stenoses: A meta-analysis. Clin Res Hepatol Gastroenterol 2016;40:666-73.

32. Caillol F, Bories E, Autret A, et al. Evaluation of pCLE in the bile duct: final results of EMID study: pCLE: impact in the management of bile duct strictures. Surg Endosc 2015;29:2661-8.

33. Meining A, Shah R, Slivka A, et al. Classification of probe-based confocal laser endomicroscopy findings in pancreaticobiliary strictures. Endoscopy 2012;44:251-7.

34. Caillol F, Filoche B, Gaidhane M, et al. Refined ProbeBased Confocal Laser Endomicroscopy Classification for Biliary Strictures: The Paris Classification. Dig Dis Sci 2013;58:1784-9.

35. Kahaleh M, Giovannini M, Jamidar P, et al. Probebased confocal laser endomicroscopy for indeterminate biliary strictures: refinement of the image interpretation classification. Gastroenterol Res Pract 2015;2015:675210.

36. Arvanitakis M, Hookey L, Tessier G, et al. Intraductal optical coherence tomography during endoscopic retrograde cholangiopancreatography for investigation of biliary strictures. Endoscopy 2009;41:696-701.

37. Tyberg A, Xu MM, Gaidhane M, et al. Second generation optical coherence tomography: Preliminary experience in pancreatic and biliary strictures. Dig Liver Dis 2018;50:1214-7.

doi: $10.21037 / \operatorname{tgh} .2020 .03 .05$

Cite this article as: Oleas R, Alcívar-Vasquez J, RoblesMedranda C. New technologies for indeterminate biliary strictures. Transl Gastroenterol Hepatol 2022;7:22. 